\title{
The Occurrence of Phosphatidylethanolamine and Glycosyl Diglycerides in Thermophilic Bacilli
}

\author{
By D. E. MINNIKIN, H. ABDOLRAHIMZADEH \\ AND J. BADDILEY \\ Microbiological Chemistry Research Laboratory, The University, \\ Newcastle upon Tyne NEI $7 R U$
}

(Received 2I March I974)

\begin{abstract}
Phosphatidylethanolamine, a common constituent of the polar lipids of Gram-negative bacteria, is consistently found in only one genus of Gram-positive bacteria, the bacilli (Goldfine, 1972). Gram-positive bacteria commonly contain diglycosyl diglycerides (Shaw \& Baddiley, 1968; Shaw, 1970) which often occur together with phosphatidylethanolamine in the bacilli. An interrelation between phosphatidylethanolamine and glycosyl diglycerides has been demonstrated in the lipids of several bacilli (Minnikin, Abolrahimzadeh \& Baddiley, I971 $a, b, 1972$ ). We have now shown that one strain of Bacillus stearothermophilus contains glycosyl diglycerides but no phosphatidylethanolamine, whereas another strain contains phosphatidylethanolamine but no glycolipids.
\end{abstract}

\section{METHODS}

Freeze-dried organisms of a strain of $B$. stearothermophilus were provided by Professor H. L. Kornberg and Dr R. K. Sundaram and had been grown $\left(55^{\circ} \mathrm{C}, 50 \mathrm{~mm}\right.$-sodium succinate as carbon source) essentially as described previously (Sundaram, Cazzulo \& Kornberg, 1969). Bacillus stearothermophilus NCIB8I57 (NCAI5I8) and the above strain were grown in a broth medium (Minnikin et al. I97 $\mathrm{a}$ ) at $55{ }^{\circ} \mathrm{C}$ for $\mathrm{I} 6 \mathrm{~h}$; harvested bacteria were washed with $\mathrm{NaCl}(0.85 \%)$ and freeze-dried.

Lipids were extracted with chloroform-methanol $(2: \mathrm{I}, \mathrm{v} / \mathrm{v})$ and examined by twodimensional thin-layer chromatography using a modification of the system described by Minnikin \& Abdolrahimzadeh (1971); Merck silica gel $\mathrm{H}$ and a second development solvent, chloroform-acetic acid-methanol-water (130:27:18:7, by vol.), were used in the present study. Spraying with a saturated solution of potassium dichromate in sulphuric acid followed by charring at $200{ }^{\circ} \mathrm{C}$ revealed spots corresponding to all the polar lipids. Specific spray reagents for lipid phosphate (Dittmer \& Lester, I964), $\alpha$-glycols (Baddiley, Buchanan, Handschumacher \& Prescott, 1956) and free amino groups (ninhydrin in butanol) were also used.

Controlled hydrolysis of lipids with alkali was carried out as described by White \& Frerman (1967). Acid hydrolysis of lipids was performed by heating in $2 \mathrm{M}-\mathrm{HCl}$ at $100{ }^{\circ} \mathrm{C}$ for $3 \mathrm{~h}$ in a sealed tube; the hydrolysate was evaporated to dryness over $\mathrm{KOH}$ in a vacuum desiccator. Water-soluble phosphates resulting from alkaline hydrolysis were examined by descending paper chromatography using the solvent systems propan-I-ol-ammonia (sp.gr. 0.88)-water (6:3:I, by vol.) (Hanes \& Isherwood, I949); butan-I-ol-pyridine-water $(6: 4: 3$, by vol.) (Jeanes, Wise \& Dimler, 195I) was used for the separation of glycosides and hexoses. Material was detected on paper chromatograms by the periodate-Schiff 


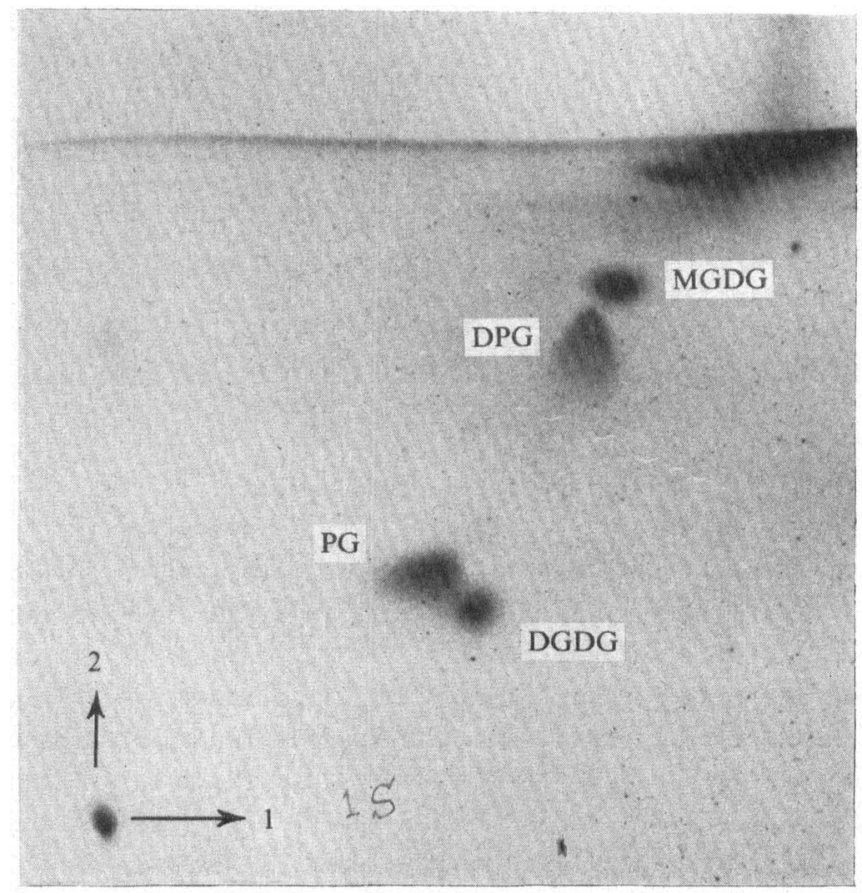

Fig. I. Two-dimensional thin-layer chrontatogram of the polar lipids of B. stearothermophilus provided by $\mathrm{H}$. L. Kornberg and T. K. Sundaram. Plates were prepared from a slurry of Merck silica gel $\mathrm{H}(40 \mathrm{~g})$ in $100 \mathrm{ml}$ aqueous sodium acetate $(0.2 \%)$. Developing solvents in the first direction were chloroform-methanol-water $(65: 25: 4$, by vol.), and in the second direction chloroform-acetic acid-methanol-water (1 30:27: 1 8:7, by vol.). Lipids were revealed by charring plates sprayed with dichromate-sulphuric acid reagent. PG, phosphatidyglycerol; DPG, diphosphatidylglycerol; MGDG, monoglucosyl diglyceride; DGDG, diglucosyl digylceride.

reagents for $\alpha$-glycols (Baddiley et al. 1956), ninhydrin reagent, and acid molybdate for phosphates (Hanes \& Ishwerood, 1949). A sample of glucosylglycerol was prepared from the lipids of Pseudomonas diminuta as described previously (Wilkinson, 1969) and diglucosylglycerol was obtained from Staphylococcus aureus (Brundish \& Baddiley, I968).

\section{RESULTS AND DISCUSSION}

A thin-layer chromatogram of the polar lipids from B. stearothermophilus provided by H. L. Kornberg \& T. K. Sundaram is shown in Fig. I. Chromatograms treated with specific spray reagents showed no ninhydrin-positive lipids, but two components with the staining properties of glycolipids were observed; the phospholipid components corresponded in chromatographic mobility and staining properties with phosphatidylglycerol and diphosphatidylglycerol. Bacteria of this strain cultivated on a broth medium showed essentially the same lipid pattern. The pattern from B. stearothermophilus NCIB8 I 57 showed components corresponding to phosphatidylglycerol, diphosphatidylglycerol, phosphatidylethanolamine (Minnikin et al. 1972) and an unidentified phospholipid; no glycolipids were detected. Paper chromatography [propan-I-ol-ammonia (sp.gr. 0.88)-water] of the watersoluble deacylated products from the lipids of both strains gave spots which corresponded to di(glycerylphosphoryl)-glycerol and glycerylphosphorylglycerol. The deacylation product from the lipids of B. stearothermophilus NCIB8I57 contained a component which 
co-chromatographed with glycerylphosphorylethanolamine; no spot corresponding to the deacylation product of the unidentified phospholipid was detected. Examination by paper chromatography (butan-I-ol-pyridine-water) of the glycosides from the first strain of $B$. stearothermophilus showed that these components stained identically to and chromatographed with the glucosylglycerol and diglucosylglycerol standards; acid hydrolysis of the lipid yielded glucose as the only sugar identified by paper chromatography in the same system.

The lipids of B. stearothermophilus 2184 (Card, Georgi \& Militzer, 1969; Card, 1973) and B. stearothermophilus B65 (Oo \& Lee, 1972) included phosphatidylethanolamine and phosphatidylglycerol. Long \& Williams (1960) suggested that phosphatidylethanolamine (cephalin) was absent from B. stearothermophilus NCA1518 (NCIB8157), but we found it to be present. Glycolipids were not investigated in the previous studies, but the results of Oo \& Lee (1972) suggest that they were absent from the lipids of B. stearothermophilus $\mathrm{B} 65$.

The apparent inability of a strain of B. stearothermophilus (Fig. 1) to synthesize phosphatidylethanolamine is remarkable as this lipid has almost invariably been encountered in bacilli (Goldfine, 1972). A phosphatidylethanolamine-deficient mutant of Bacillus subtilis (Marburg) has, however, been obtained (Beebe, I971) and certain continuous cultures of B. subtilis (Marburg) lack this lipid (Minnikin et al. 1972). The absence of glycolipids from $B$. stearothermophilus NCIB8 57 is surprising since most bacilli also contain glycosyl diglycerides (Shaw, 1970). Cultures of Bacillus cereus $\mathrm{T}$ have occasionally been found to contain no detectable amounts of glycolipids (Minnikin et al. I97 I a). The present results support the proposed interchangeability of phosphatidylethanolamine and glycosyl diglycerides in the membranes of bacilli (Minnikin et al. 1971 $a, b, 1972$ ) and suggest that polar lipid analysis may be a valuable chemotaxonomic technique for the classification of thermophilic bacilli.

Thanks are due to Professor H. L. Kornberg and Dr T. K. Sundaram for provision of B. stearothermophilus.

\section{REFERENCES}

Baddiley, J., Buchanan, J. G., Handschumacher, R. E. \& Prescott, J. F. (1956). Chemical studies in the biosynthesis of purine nucleotides. I. The preparation of $N$-glycylglycosylamines. Journal of the Chemical Society, $2818-2823$.

BEEBE, J. L. (197I). Isolation and characterisation of a phosphatidylethanolamine-deficient mutant of Bacillus subtilis. Journal of Bacteriology 107, 704-7 II.

Brundish, D. E. \& Baddiley, J. (1968). Synthesis of glucosylglycerols and diglucosylglycerols, and their identification in small amounts. Carbohydrate Research 8, 308-3I 6.

CARD, G. L. (I973). Metabolism of phosphatidylglycerol, phosphatidylethanolamine, and cardiolipin of Bacillus stearothermophilus. Journal of Bacteriology 114, I $125-1137$.

Card, G. L., Georgi, C. E. \& Militzer, W. E. (I969). Phospholipids from Bacillus stearothermophilus. Journal of Bacteriology $97,186-192$.

DitTmer, J. C. F. \& Lester, R. L. (1964). A simple, specific spray for the detection of phospholipids on thin-layer chromatograms. Journal of Lipid Research 5, 126-127.

Goldfine, H. (1972). Comparative aspects of bacterial lipids. In Advances in Microbial Physiology, vol. 8, pp. I-58. Edited by A. H. Rose and D. W. Tempest. London: Academic Press.

Hanes, C. R. \& Isherwood, F. A. (1949). Separation of the phosphoric esters on the filter paper chromatogram. Nature, London $\mathbf{1 6 4}, 1$ 107-I I 12.

Jeanes, A., Wise, C. S. \& Dimler, R. J. (I95I). Improved techniques in paper chromatography of carbohydrates. Analytical Chemistry 23, 415-420.

LoNG, S. K. \& Williams, O. B. (I960). Lipids of Bacillus stearothermophilus. Journal of Bacteriology $\mathbf{7 9}$, 629-637. 
Minnikin, D. E. \& Abdolrahimzadeh, H. (1971). Thin-layer chromatography of bacterial lipids on sodium acetate-impregnated silica gel. Journal of Chromatography 63, 452-454.

Minnikin, D. E., Abdolrahmizadeh, H. \& Baddiley, J. (1971 $a$ ). The interrelation of phosphatidylethanolamine and glycosyl diglycerides in bacterial membranes. Biochemical Journal 124, 447-448.

Minnikin, D. E., Abdolrahimzadeh, H. \& Baddiley, J. (1971 b). The interrelation of polar lipids in bacterial membranes. Biochimica et biophysica acta 249, 65 I-655.

Minnikin, D. E., Abdolrahimzadeh, H. \& Baddiley, J. (1972). Variation of polar lipid composition of Bacillus subtilis (Marburg) with different growth conditions. FEBS Letters 27, 16-18.

Oo, K. C. \& LEE, Y. H. (1972). The phospholipids of a facultatively thermophilic strain of Bacillus stearothermophilus. Journal of Biochemistry 71, $108 \mathrm{I}-1084$.

SHAW, N. (1970). Bacterial glycolipids. Bacteriological Reviews 34, 365-377.

Shaw, N. \& Baddiley, J. (I968). Structure and distribution of glycosyl diglycerides in bacteria. Nature, London 217, I42-I 44 .

Sundaram, T. K., Cazzulo, J. J. \& Kornberg, H. L. (1969). Anaplerotic CO 2 fixation in mesophilic and thermophilic bacilli. Biochimica et biophysica acta I92, 355-357.

White, D. C. \& Frerman, F. E. (1967). Extraction, characterisa.ion and cellular localization of the lipids of Staphylococcus aureus. Journal of Bacteriology 94, 1854-1867.

Wilkinson, S. G. ( 1969). Lipids of Pseudomonas diminuta. Biochimica et biophysica acta 187, 492-500. 